Published as Batterburv. S.P.J. 2014. Human Research Ethics Committees: beyond critique to participation. The Australian Journal of Anthropology. 25(3): 285-286.

\title{
Human Research Ethics Committees: Beyond Critique to Participation
}

Simon Batterbury

Associate Professor of Environmental Studies, University of Melbourne

There is frequent criticism by social scientists of Human Research Ethics Committees (HREC). They are accused of 'ethics creep', having expanded from their earliest focus in the medical and veterinary sciences following a 1974 ruling in the USA (1985 in Australia) (Haggerty, 2004; Dyer and Demeritt 2009). Ethics committees now review any university research involving human 'subjects’ (Borenstein 2008).

Dissatisfaction about the practice of ethics review is especially strong in anthropology, where it is often hard to specify in advance what will be done in a given project and participants are often already known to the researcher (Cowlishaw 2013). Ethnography’s ‘...immersive and exploratory nature' is difficult to predict or constrain in advance of fieldwork (Chenhall et al. 2011: 17). Researchers dislike being forced by their institutions, which may be running scared of lawsuits or costly insurance claims for projectsgone-wrong, to justify and specify their work (Cowlishaw 2013).

I have some sympathy. My own expertise has involved research in six countries over 20 years, initially with no ethics approval. But I have been chairing a Faculty 'minimal risk' ethics committee for two and a half years. The pile of applications now stands $25 \mathrm{~cm}$ high. Members are all social scientists including a PhD student, animal welfare expert and a parttime administrator. This is not unusual (Dunscombe et al. 2013). We debate but do not approve applications involving First Peoples and children, which are dealt with by a university-wide committee (Clough et al., 2013).

The critique of the ethics process by some anthropologists is questionable. The claim that 'In our experience, Australian HRECs frequently judge qualitative research by the logic 
of quantitative methods, due to a lack of capacity and skills in qualitative research...' (Chenhall et al. 2011: 17) is certainly incorrect in our case. Our understanding of anthropological research is not a '...caricature of the colonial anthropologist in a pith helmet, exploiting the knowledge he gains from naive Indigenous people and never returning anything to the community’ (Cowlishaw 2013).

Committees are more limited than they may seem: they assure pre-project 'procedural ethics', scrutiny and feedback on applications, but cannot oversee 'ethics in practice' during fieldwork. There is little post-hoc review of projects (Guillemin and Gillam 2004). Applications we reject usually lack a coherent methodological framework (what sort of people will be talked to, where, how, when, and how to engage with them?). Some have invasive questions or risks that appear to be unjustified. Consent has to be informed, not coerced. None of this is really too much to ask. In most cases, applications are returned for minor revision and then approved rapidly.

How could the process be improved? Since it is part of the neoliberal approach to university management (i.e. minimising lawsuits and risks), it will remain a fixture of contemporary institutions. We have to make the best of it. The best response anthropologists can make is to be responsible for ethics review, through committee membership. Sympathy for ethnographic projects and risks increases if knowledgeable social scientists actually serve on the HREC. Offering helpful rather than obstructive suggestions is an unwritten obligation of any ethics committee.

In conclusion, the best way to smooth anthropologists’ progress through ethics review is to participate. If the HREC is knowledgeable and helpful, then the accusation of ignorance of anthropological methods is hard to sustain. In our HREC, there is no dismissal of ethnographic techniques. Others suggest we are not alone (Abbott and Grady 2011; Clough et al. 2013; McMurphy et al. 2013). Our attitude is (I hope) constructive and sympathetic. This 
reflects my general academic philosophy; collegial service accompanies writing articles, getting grants and seeking promotion. HREC committee work is thankless, without personal kudos, and is largely unrecognised.

It is more radical to deploy citizen power, than to complain about its absence in the ethics review process.

Abbott L. and Grady C. 2011 A systematic review of the empirical literature evaluating IRBs: what we know and what we still need to learn. Journal of Empirical Research on Human Research Ethics 6(1): 3-20.

Borenstein, J. 2008 The expanding purview: institutional review boards and the review of human subjects research. Accountability in Research 15:188-204.

Chenhall, R., Senior, K. Belton, S. 2011 Negotiating human research ethics: Case notes from anthropologists in the field. Anthropology Today 27(5): 13-17.

Clough B.A., M.M. Campbell, T.A. Aliyeva, N.J. Mateo, M. Zarean and A. O’Donovan. 2013 Protocols for protection of human participants. Journal of Empirical Research on Human Research Ethics 8(3): 2-11.

Cowlishaw, G. 2013 A new protection policy? Inside Story Dec. 17. http://inside.org.au/anew-protection-policy/

Dyer S. and Demeritt, D. 2009 Un-ethical review? Why it is wrong to apply the medical model of research governance to human geography. Progress in Human Geography 33(1): 46-64.

Dunscombe, K., Horsley, P., Guillemin, M., Gillam, L. 2013 HREC administrators: the invisible link. Centre for Health and Society, the University of Melbourne, Australia. http://chs.unimelb.edu.au/_data/assets/pdf_file/0004/787162/HREC_Administrators_Report 2013.pdf

Guillemin, M. and L. Gillam 2004 Ethics, reflexivity, and ‘ethically important moments’ in research. Qualitative Inquiry 10(2): 261-280.

Haggerty, K.D. 2004 Ethics creep: governing social science research in the name of ethics. Qualitative Sociology 27 (4): 391-414.

McMurphy S, J. Lewis and P. Bulos. 2013 Extending the olive branch. Journal of Empirical Research on Human Research Ethics 8(4): 29-36. 


\section{University Library}

\section{- M M N E R VA A gateway to Melbourne's research publications}

Minerva Access is the Institutional Repository of The University of Melbourne

Author/s:

Batterbury, S

Title:

Human research ethics committees: Beyond critique to participation

Date:

2014-12-01

Citation:

Batterbury, S. (2014). Human research ethics committees: Beyond critique to participation. AUSTRALIAN JOURNAL OF ANTHROPOLOGY, 25 (3), pp.385-386. https://doi.org/10.1111/ taja.12109_6.

Persistent Link:

http://hdl.handle.net/11343/45251 